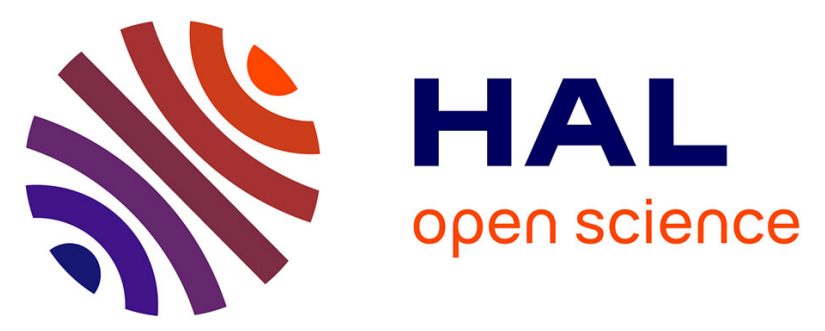

\title{
The preparation of carbon nanotube (CNT)/copper composites and the effect of the number of CNT walls on their hardness, friction and wear properties
}

Christophe Guiderdoni, Ekaterina Pavlenko, Viviane Turq, Alicia Weibel, Pascal Puech, Claude Estournès, Alain Peigney, Wolfgang Bacsa, Christophe Laurent

\section{To cite this version:}

Christophe Guiderdoni, Ekaterina Pavlenko, Viviane Turq, Alicia Weibel, Pascal Puech, et al.. The preparation of carbon nanotube $(\mathrm{CNT}) /$ copper composites and the effect of the number of CNT walls on their hardness, friction and wear properties. Carbon, 2013, vol. 58, pp. 185-197. 10.1016/j.carbon.2013.02.049 . hal-00869492

\section{HAL Id: hal-00869492 https://hal.science/hal-00869492}

Submitted on 3 Oct 2013

HAL is a multi-disciplinary open access archive for the deposit and dissemination of scientific research documents, whether they are published or not. The documents may come from teaching and research institutions in France or abroad, or from public or private research centers.
L'archive ouverte pluridisciplinaire HAL, est destinée au dépôt et à la diffusion de documents scientifiques de niveau recherche, publiés ou non, émanant des établissements d'enseignement et de recherche français ou étrangers, des laboratoires publics ou privés. 


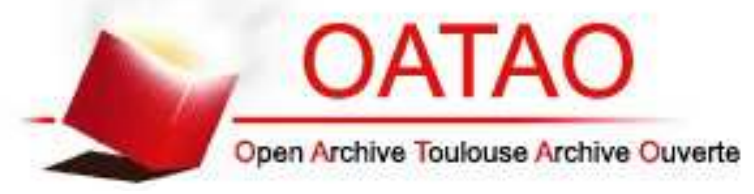

\section{Open Archive TOULOUSE Archive Ouverte (OATAO)}

OATAO is an open access repository that collects the work of Toulouse researchers and makes it freely available over the web where possible.

This is an author-deposited version published in : http://oatao.univ-toulouse.fr/ Eprints ID : 9361

To link to this article : DOI:10.1016/j.carbon.2013.02.049

URL : http://dx.doi.org/10.1016/j.carbon.2013.02.049

To cite this version : Guiderdoni, Christophe and Pavlenko, Ekaterina and Turq, Viviane and Weibel, Alicia and Puech, Pascal andEstournès, Claude and Peigney, Alain and Bacsa, Wolfgang and Laurent, Christophe. The preparation of carbon nanotube $(C N T) / c o p p e r$ composites and the effect of the number of CNT walls on their hardness, friction and wear properties. (2013) Carbon, vol. 58. pp. 185-197. ISSN 0008-6223

Any correspondance concerning this service should be sent to the repository administrator: staff-oatao@ listes-diff.inp-toulouse.fr 


\title{
The preparation of carbon nanotube (CNT)/copper composites and the effect of the number of CNT walls on their hardness, friction and wear properties
}

\author{
Ch. Guiderdoni ${ }^{a}$, E. Paulenko ${ }^{b}$, V. Turq $^{a}$, A. Weibel ${ }^{a}$, P. Puech ${ }^{b}$, C. Estournès ${ }^{c}$, \\ A. Peigney ${ }^{a}, \mathrm{~W}$. Bacsa $^{b}$, Ch. Laurent ${ }^{a, *}$ \\ a Université de Toulouse, Institut Carnot CIRIMAT, UMR CNRS-UPS-INP 5085, Université Paul-Sabatier, 118 route de Narbonne, \\ 31062 Toulouse cedex 9, France \\ ${ }^{\mathrm{b}}$ CEMES, UPR 8011, CNRS-Université de Toulouse, 29, rue Jeanne Marvig, BP 94347, 31055 Toulouse, France \\ c CNRS, Institut Carnot CIRIMAT, UMR CNRS-UPS-INP 5085, 118 route de Narbonne, 31062 Toulouse cedex 9, France
}

\begin{abstract}
A B S T R A C T
Carbon nanotubes with 2, 3, 8 and 20 walls are mixed with a copper powder (micrometer sized) and consolidated by spark plasma sintering. The microhardness of resulting composites is found to be over $50 \%$ higher than that for $\mathrm{Cu}$ and the friction coefficient against a steel ball is decreased by a factor of 3-4 while the wear and wear rate are reduced by a factor of 10-20. Raman maps of selected specimens outside and inside the worn surface show that double-wall carbon nanotubes remain intact. The reasons for the effect of the number of walls and carbon content are discussed.
\end{abstract}

\section{Introduction}

Metal-matrix composites containing carbon nanotubes (CNTs) are promising materials for structural applications because of the unique mechanical properties of the CNTs [ 1 and references therein]. Self-lubricating materials, preventing the need for liquid lubricants, are of particular interest and reports on such materials, in particular CNT/Cu composites [2-9], are increasingly abundant. The homogeneity of the CNT dispersion, good interfacial bonding and a high relative density are key points to achieve a higher microhardness, a lower friction and a lower wear. However, the comparison of the results reported by different groups is hampered notably because different CNTs are used, the preparation routes differ markedly and the tribological testing conditions (counterface, load, distance, relative humidity) vary widely. When using double-walled CNTS (DWCNTs) [9], a doubling of the Vickers microhardness and a fourfold decrease of the average friction coefficient against steel or alumina, compared to pure $\mathrm{Cu}$, were obtained for a carbon loading ( $5 \mathrm{vol} . \%)$ significantly lower than those (10-20 vol.\%) reported when using multi-walled CNTs (MWCNTs) $[2-4,7,8]$. Indeed, a given DWCNT weighs much less than a MWCNT of the same length [10] and therefore many more DWCNTs are present for a given carbon weight loading, which can greatly modify the matrix microstructure and ultimately give better results for lower carbon loadings, as was also found for DWCNT/ceramic composites [11-13]. Thus, one aim of this work is to study the influence of the volume carbon content on microhardness, friction and wear. We change the volume carbon content by increasing the average number of walls (2, 3, 8 and 20) of the CNTs. The results will be compared with those of a previous study [9] where the volume carbon content was changed by increasing the proportion of DWCNTs in the composites. A second aim is to perform a detailed Raman spectroscopy study of selected specimens, outside and inside the wear

\footnotetext{
${ }^{*}$ Corresponding author.

E-mail address: laurent@chimie.ups-tlse.fr (Ch. Laurent).
} 
tracks, in order to shed light on the role and the state of the CNTs.

\section{Experimental methods}

\subsection{Raw materials}

A commercial Cu powder (Alfa Aesar 0.5-1.5 $\mu \mathrm{m}$ ) was used for the study. Several types of CNT samples with a different average number of walls, were selected as described later in this section. For the sake of clarity, the sample where $N$ is equal to 2 is noted DWCNT and the samples where $N$ is equal to 3 , 8 and 20 are noted 3WCNT, 8WCNT and 20WCNT, respectively. The DWCNTs were synthesized by methods reported earlier [14,15]. Briefly, a $\mathrm{Mg} 0.99\left(\mathrm{Co}_{0.75} \mathrm{Mo}_{0.25}\right)_{0.01} \mathrm{O}$ powder prepared by combustion synthesis was submitted to a catalytic chemical vapor deposition (CCVD) treatment $\left(\mathrm{H}_{2}-\mathrm{CH}_{4}\right.$ with $18 \mathrm{~mol} \% \mathrm{CH}_{4}$, maximum temperature $1000^{\circ} \mathrm{C}$ ), producing a $\mathrm{CNT} / \mathrm{Co}-\mathrm{Mo} / \mathrm{MgO}$ powder. This powder was soaked in a $37 \%$ $\mathrm{HCl}$ aqueous solution in order to dissolve $\mathrm{MgO}$ and most of the cobalt- and molybdenum compounds [16]. The soobtained suspension of DWCNTs was washed with deionized water until neutrality and subsequently filtered and washed with ethanol. Finally, the sample was dried overnight at $80^{\circ} \mathrm{C}$ in air. The 3 WCNTs were synthesized by the same route, the starting catalytic material being a $\mathrm{Mg} 0.99\left(\mathrm{Co}_{0.33} \mathrm{Mo}_{0.67}\right)_{0.01}$ powder $[15,17]$. The $8 \mathrm{WCNT}$ and 20WCNT samples were purchased from Nanocyl (Belgium) and Nanothinx (Greece), respectively. They were prepared using a CCVD route but the precise experimental details are not known to the authors.

The CNT samples were investigated by high-resolution transmission electron microscopy (HRTEM, JEOL JEM 2100F operated at $120 \mathrm{kV}$ ). Typical images are shown in Fig. 1. The DWCNTs (Fig. 1a and b) and 3WCNTs (Fig. 1c and d) tend to form bundles, which is favored by their small diameter, their high aspect ratio and van der Waals interactions [14]. The presence of structural defects and non-tubular carbon may result from degradation under the electron beam. The 8WCNTs (Fig. 1e and f) and 20WCNTs (Fig. 1g and h) are not bundled and most CNTs present important structural defects, such as kinks, uncompleted walls, bamboo-like structure and variation of the diameter, along the length of the CNTs.

The number of walls was measured for about 100 CNTs on HRTEM images. The average number of walls $(N)$ is shown in Table 1. For the DWCNT sample, the distribution of the number of walls (Fig. 2a) shows mostly DWCNTs (80\%) together with single-wall CNTs (15\%) and 3WCNTS (5\%). N is equal to 1.9 which was rounded to 2. For the 3WCNT specimen (Fig. 2b), CNTs with 1-7 walls are observed. The DWCNTs are still dominant $(40 \%)$ with 3WCNTs $(29 \%)$ the second most abundant CNTs. $N$ is equal to 2.7 which was rounded to 3 . For the 8WCNT sample (Fig. 2c), CNTs with 3-22 walls are observed. The 8 WCNTs are dominant $(30 \%)$ with 7 WCNTs and 9WCNTs (both $16 \%$ ) the second most abundant CNTs. $N$ is equal to 8.5 which was rounded to 8 . For the 20WCNT sample (Fig. 2d), the distribution of the number of walls is very wide, mostly in the range 8-37, and CNTs with 50,52 and 56 walls were also observed. The CNTs with 17 walls are dominant but barely (only $10 \%$ ). $\mathrm{N}$ is equal to 19.8 which was rounded to 20. Note however that no 20WCNT was actually observed. Although the notion of an average number of walls is admittedly less pertinent for the 20CNT specimen than for the DWCNT, 3WCNT and 8WCNT samples, it was thought useful to use it, as well as the codename 20WCNT, as opposed to MWCNT, which is indeed too vague. The average external diameter ( $d_{\text {ext }}-$ Table 1$)$ was also derived from HRTEM measurements. The present values are in excellent agreement with the empirical law giving the correlation with $\mathrm{N}$ for a population of MWCNTs prepared by CCVD [18].

Other characteristics are listed in Table 1: the theoretical density of the CNTs $\left(\rho_{0}\right)$ calculated using the CNT density chart [10], the specific surface area of the samples $\left(\mathrm{S}_{\mathrm{CNT}}\right)$ measured by the BET method using $\mathrm{N}_{2}$ adsorption at liquid- $\mathrm{N}_{2}$ temperature, which decreases when $N$ is higher in agreement with calculations from geometrical data [19] and the carbon content in the sample $\left(C_{n}\right)$ determined by flash combustion. It was also attempted to evaluate CNT length ( $L$ - Table 1 ) on TEM images, although it is very difficult for the DWCNT and 3WCNT samples because the CNTs tend to form bundles as noted above.

\subsection{Powders}

The CNT/Cu powders were prepared by a rapid mixing route involving short-time sonication and freeze-drying, without oxidative acidic treatment or ball-milling in order to avoid damaging the CNTs [9]. The surface area developed by the total amount of CNTs introduced in the samples was kept as a constant. It was chosen equal to that $\left(64 \mathrm{~m}^{2}\right)$ found for the sample prepared with DWCNTs for a carbon content equal to 5 vol.\%, which was the best earlier sample [9]. The appropriate quantity of CNTs was dispersed in deionized water using a sonotrode (Bioblock Scientific VibraCell 75042) for a few seconds, after which the $\mathrm{Cu}$ powder was added. The ultrasonic agitation was maintained for one minute. Then, the vessel containing the CNT/Cu suspension was immediately immersed in liquid $\mathrm{N}_{2}$ for 2 min and was freeze-dried (Christ alpha 2-4 LD, Bioblock Scientific) at $-40^{\circ} \mathrm{C}$ for $48 \mathrm{~h}$ in a primary vacuum $(12 \mathrm{~Pa})$. The mixed powders are noted $\mathrm{P} 2$, P3, P8 and P20 hereafter.

\subsection{Spark plasma sintering}

The $\mathrm{Cu}$ and CNT/Cu powders were densified by SPS (Dr. Sinter 2080, SPS Syntex Inc., Japan). They were loaded into a $20 \mathrm{~mm}$ inner diameter graphite die. A sheet of graphitic paper was placed between the punch and the powder as well as between the die and the powder for easy removal. This ensemble is known as the stack. The powders were sintered in vacuum (residual cell pressure $<10 \mathrm{~Pa}$ ). A pulse pattern of twelve current pulses followed by two periods of zero current was used. A heating rate of $100^{\circ} \mathrm{C} / \mathrm{min}$ was used from room temperature to $700^{\circ} \mathrm{C}$, where a six minutes dwell was applied. The temperature was controlled using a thermocouple introduced in a little hole ( $5 \mathrm{~mm}$ deep) located on the outer surface of the die. A uniaxial charge (corresponding to $100 \mathrm{MPa}$ on the pellet) was gradually applied within the first minute of the dwell at $700{ }^{\circ} \mathrm{C}$ and maintained during the remaining five minutes. 

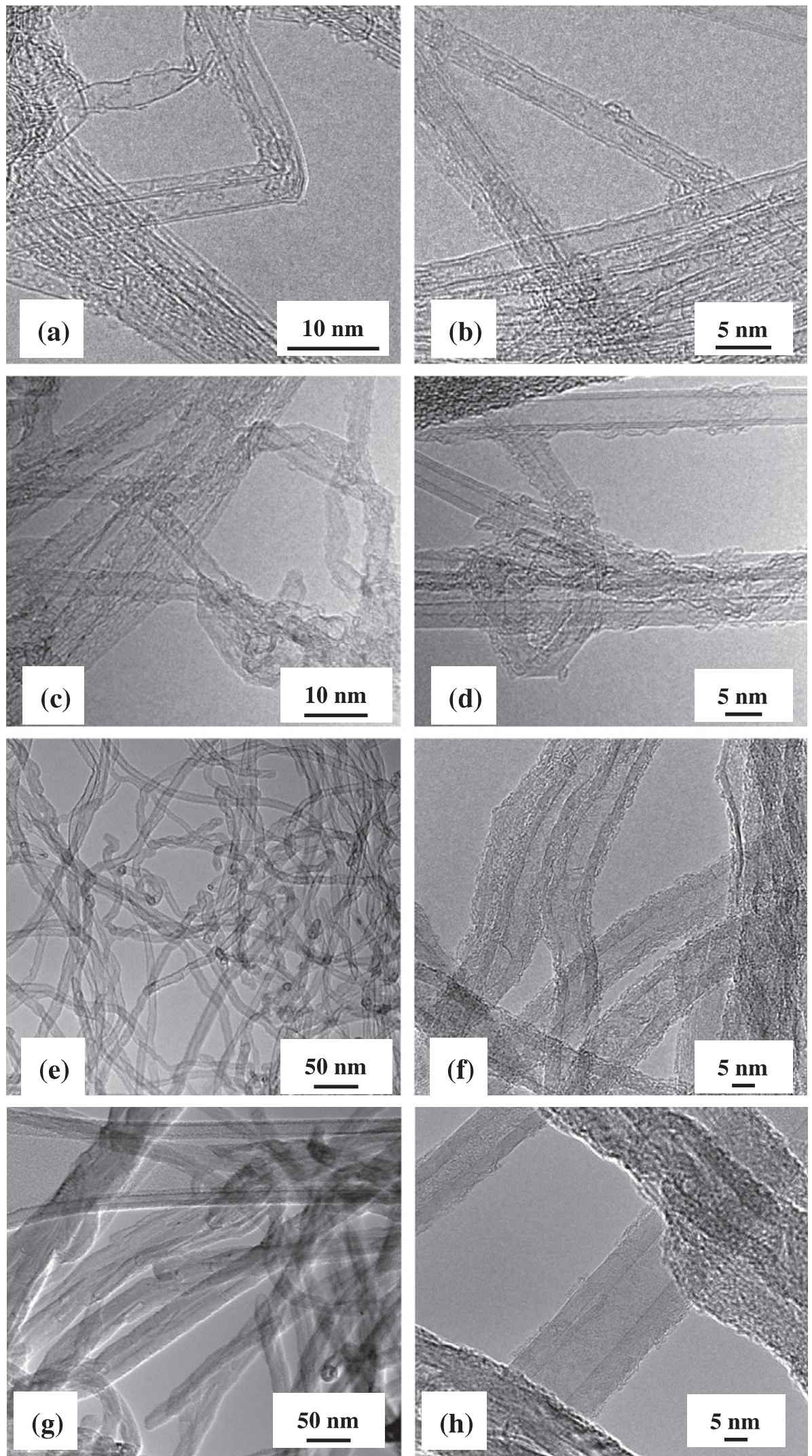

Fig. 1 - TEM and HRTEM images of the DWCNT ( $a$ and b), 3WCNT (c and d), 8WCNT (e and f) and 20WCNT (g and $h$ ) samples.

Natural cooling was applied down to room temperature and the uniaxial load was gradually released during the same time. The sintered specimens were in form of pellets $20 \mathrm{~mm}$ in diameter and about $2 \mathrm{~mm}$ thick. The pellets were polished down to $0.25 \mu \mathrm{m}$ using diamond slurries. The sintered specimens will be noted as $\mathrm{Cu}, \mathrm{S} 2, \mathrm{~S} 3, \mathrm{~S} 8$ and S20 hereafter. 
Table 1 - Average number of walls $(N)$, average external diameter $\left(d_{\text {ext }}\right)$ and approximate length $(L)$ of the CNTs, theoretical density of the CNT $\left(\rho_{0}\right)$, specific surface area of the CNT samples $\left(S_{\mathrm{CNT}}\right)$, carbon content in the CNT samples $\left(\mathrm{C}_{n}\right)$; the balance is mostly water and residual metal catalyst.

\begin{tabular}{|c|c|c|c|c|c|c|}
\hline Specimen & $N$ & $d_{\text {ext }}(n m)$ & $L(\mu \mathrm{m})$ & $\rho\left(\mathrm{g} / \mathrm{cm}^{3}\right)$ & $\mathrm{S}_{\mathrm{CNT}}\left(\mathrm{m}^{2} / \mathrm{g}\right)$ & $\mathrm{C}_{n}$ (wt.\%) \\
\hline DWCNT & $1.9 \# 2$ & 2.0 & $>5$ & 1.8 & 1000 & 88.4 \\
\hline 3WCNT & $2.7 \# 3$ & 3.5 & $>5$ & 1.9 & 534 & 90.5 \\
\hline 8WCNT & $8.5 \# 8$ & 10.2 & $<1.5$ & 1.8 & 242 & 91.8 \\
\hline 20WCNT & 19.8 \# 20 & 19.6 & $<4$ & 2.1 & 92 & 88.2 \\
\hline
\end{tabular}
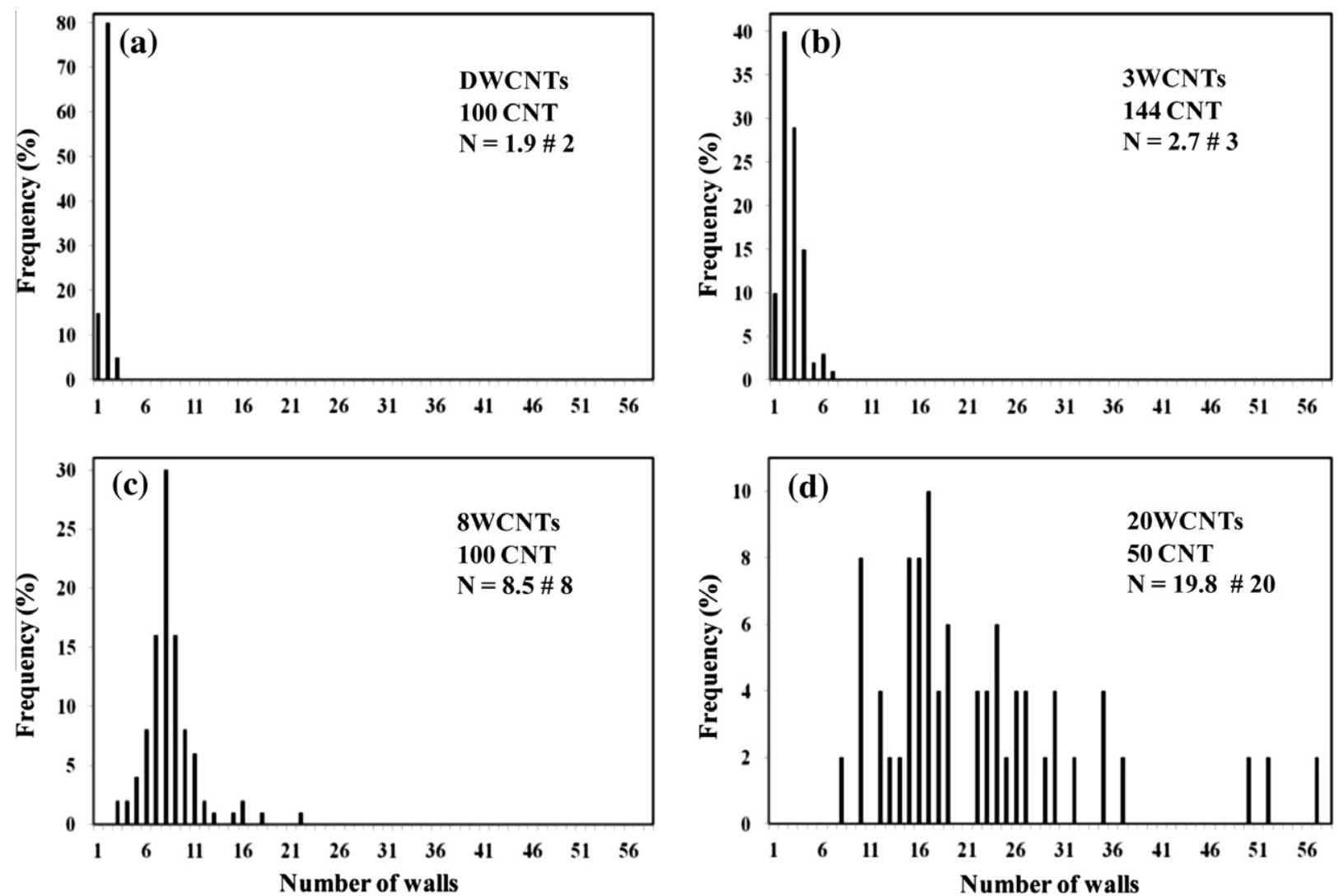

Fig. 2 - Distribution of the number of walls as deduced from the measurement of about 100 CNTs on HRTEM images for the DWCNT (a), 3WCNT (b), 8WCNT (c) and 20WCNT (d) samples.

\subsection{Characterization}

The specific surface area of the powders was measured by the BET method using $\mathrm{N}_{2}$ adsorption at liquid- $\mathrm{N}_{2}$ temperature (Micromeritics FlowSorb II 2300). The reproducibility of the results is $\pm 3 \%$. The density of the pellets ( $d-$ Table 2 ) was calculated from their weight and dimensions. The theoretical density of the pellets ( $d_{0}$ - Table 2$)$ was calculated using $8.92 \mathrm{~g} / \mathrm{cm}^{3}$ for $\mathrm{Cu}$ and the appropriate CNT theoretical density $\left(\rho_{0}-\right.$ Table 1$)$. The relative density was then calculated from the $d$ and $d_{0}$ values ( $\delta$-Table 2). The powders and pellets were observed by field-emission-gun scanning electron microscopy (FESEM, JEOL JSM 6700F). For observation of the polished surfaces, the pellets were etched in $\mathrm{HNO}_{3}$ (room temperature, $10 \mathrm{~s}$ ). The wear tracks were observed by interferential rugosimetry (Zygo NewView 100). Selected samples were studied by Raman spectroscopy (XPlora spectrometer in backscattering geometry and using $632 \mathrm{~nm}$ laser excitation). The laser power was fixed to $1 \mathrm{~mW}$ and we used a $100 \times$ objective. For Stokes/ Anti-Stokes measurements, a Dilor spectrometer with the same experimental conditions was used.

\subsection{Microhardness and tribological testing}

The indentation tests $(0.1 \mathrm{~N}$ for $10 \mathrm{~s}$ in air at room temperature) were performed on the fresh polished surface of the specimens by loading with a Vickers indenter (Shimadzu HMV 2000). The calculated microhardness values are the average of ten measurements. Friction tests were performed using a ball-on-flat geometry in reciprocating mode (CSM Tribometer), at room temperature in ambient air with a 40-60\% relative humidity. A $100 \mathrm{C} 6$ steel ball $6 \mathrm{~mm}$ in diameter was used against flat $\mathrm{Cu}$ and $\mathrm{CNT} / \mathrm{Cu}$ sample fresh polished surfaces. The maximum sliding speed was fixed at $2 \mathrm{~cm} / \mathrm{s}$. The testing 
Table 2 - Average number of walls $(N)$ of the CNTs, carbon content in weight $\left(C_{w}\right)$ and in volume $\left(C_{v}\right)$, density $(d)$, theoretical density $\left(d_{0}\right)$ and relative density $(\delta)$ of the sintered specimens, Vickers microhardness $\left(H_{V}\right)$, average friction coefficient for $1 \mathrm{~N}$ $\left(\mu_{1}\right)$ and $5 \mathrm{~N}$ loads $\left(\mu_{5}\right)$, wear track half-width $(r)$, wear track depth $(D)$, wear volume $\left(V_{w}\right)$ and load-normalized wear rate $(W)$.

\begin{tabular}{llllllllllllll} 
Specimen & $N$ & $C_{\mathrm{w}}$ (wt.\%) & $C_{\mathrm{v}}(\mathrm{vol} . \%)$ & $d\left(\mathrm{~g} / \mathrm{cm}^{3}\right)$ & $d_{\mathrm{o}}\left(\mathrm{g} / \mathrm{cm}^{3}\right)$ & $\delta(\%)$ & $H_{\mathrm{V}}$ & $\mu_{1}$ & $\mu_{5}$ & $r(\mathrm{~mm})$ & $D(\mathrm{~mm})$ & $V_{\mathrm{w}}\left(\mathrm{mm}^{3}\right)$ & $\mathrm{W}\left(\mathrm{mm}^{3} / \mathrm{m} \mathrm{N}\right)$ \\
\hline $\mathrm{Cu}$ & - & 0 & 0 & 8.74 & 8.92 & 98 & 50 & 0.78 & 0.78 & 0.322 & 0.0354 & 0.450 & 0.00300 \\
$\mathrm{~S} 2$ & 2 & 1.1 & 5.0 & 8.22 & 8.56 & 96 & 82 & 0.36 & 0.24 & 0.221 & 0.0051 & 0.044 & 0.00030 \\
$\mathrm{~S} 3$ & 3 & 2.0 & 8.4 & 7.08 & 8.33 & 85 & 80 & 0.24 & 0.17 & 0.226 & 0.0051 & 0.052 & 0.00034 \\
$\mathrm{~S} 8$ & 8 & 4.2 & 17.1 & 6.32 & 7.70 & 82 & 77 & 0.19 & 0.21 & 0.171 & 0.0032 & 0.022 & 0.00014 \\
$\mathrm{~S} 20$ & 20 & 10.4 & 33.2 & 4.86 & 6.66 & 73 & 61 & 0.21 & 0.21 & 0.342 & 0.0100 & 0.135 & 0.00090 \\
\hline
\end{tabular}

length for one cycle is about $6 \mathrm{~mm}$ and a total of 500 cycles were performed for one test. The tests were performed at 1 and $5 \mathrm{~N}$. No higher load was tested in order to limit the pellets damage and to avoid changing the contact geometry. The frictional force transferred to a load cell was recorded throughout the test. Wear tests were performed in rotary mode (constant speed equal to $2 \mathrm{~cm} / \mathrm{s}$ ) using a $10 \mathrm{~N}$ load. Flat-surfaces $20 \mathrm{~mm}$ in diameter were rubbed against a $100 \mathrm{C} 6$ steel ball $6 \mathrm{~mm}$ in diameter. The testing length $(L)$ is $15 \mathrm{~m}$ in order to stay in the mild-wear regime.

\section{Results and discussion}

\subsection{Powders and sintered specimens}

FESEM observations of the powders revealed that the S2 powder is more homogeneous, the mixing conditions having been optimized for this sample [9]. For example, two areas of S20
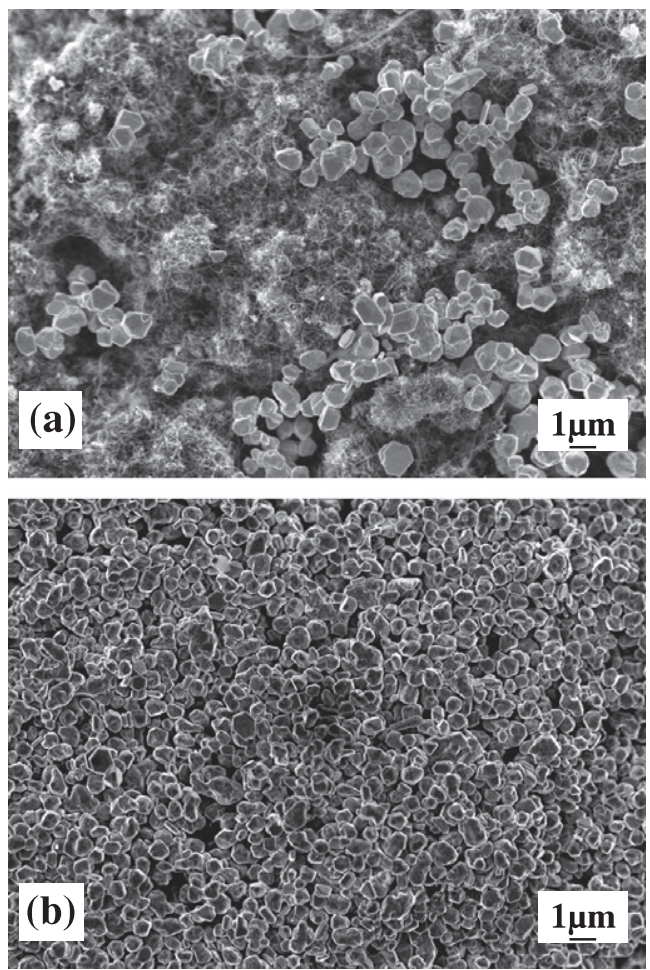

Fig. 3 - FESEM images of two different areas of S20, one showing many CNTs (a) and the other showing no CNTs (b), revealing a lack of homogeneity of the CNT distribution.

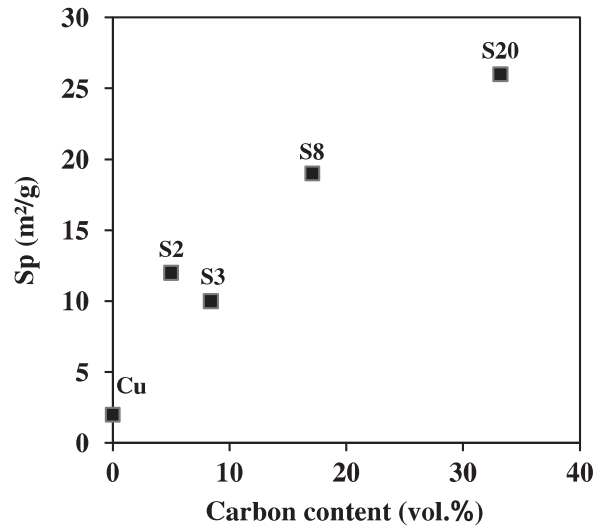

Fig. 4 - Specific surface area of the CNT/Cu powder versus carbon content.

are shown, one showing many CNTs (Fig. 3a) and one showing no CNTs (Fig. 3b). A direction for future work is to finetune the mixing conditions with the $\mathrm{Cu}$ powder according to the types of CNTs. The equivalent carbon proportions in the composites, both in weight and in volume, are given in Table 2. The specific surface area $\left(\mathrm{S}_{\mathrm{P}}-\right.$ Fig. 4$)$ of the $\mathrm{Cu}$ powder is equal to $2 \mathrm{~m}^{2} / \mathrm{g}$. It is in the range $10-26 \mathrm{~m}^{2} / \mathrm{g}$ for the mixed powders, reflecting the presence of the CNTs.

The density of the pellets ( $d$ - Fig. 5 and Table 2 ) is higher than $95 \%$ for $\mathrm{Cu}$ and S2 and decreases regularly upon the increase in carbon content, reaching only $73 \%$ for S20 (carbon content equal to $33.2 \mathrm{vol} \%$ ).

In agreement with the observation made for the powders, FESEM observations of the polished surfaces reveal some in homogeneity in the dispersion of the CNTs. Typical images reveal CNT bundles covering the surface for S2 (Fig. 6a), apparent alignment possibly generated during polishing and CNT agglomerates between $\mathrm{Cu}$ grains for S2O (Fig. 6b). It was not attempted to measure the $\mathrm{Cu}$ grain size, because as mentioned above, there is a certain lack of homogeneity in the CNT dispersion and thus, there is a wide distribution of the grain size of $\mathrm{Cu}$ in the sintered samples: very small grains $(<100 \mathrm{~nm})$ in areas with many CNTs and larger grains elsewhere. Indeed, it is known that the presence of the CNTs hampers $\mathrm{Cu}$ diffusion and grain growth $[9,20]$.

\subsection{Microhardness and tribological properties}

The Vickers microhardness ( $\mathrm{H}_{\mathrm{V}}-$ Fig. 7 and Table 2) for the $\mathrm{Cu}$ specimen is equal to 50. It is significantly higher for S2, S3 and 


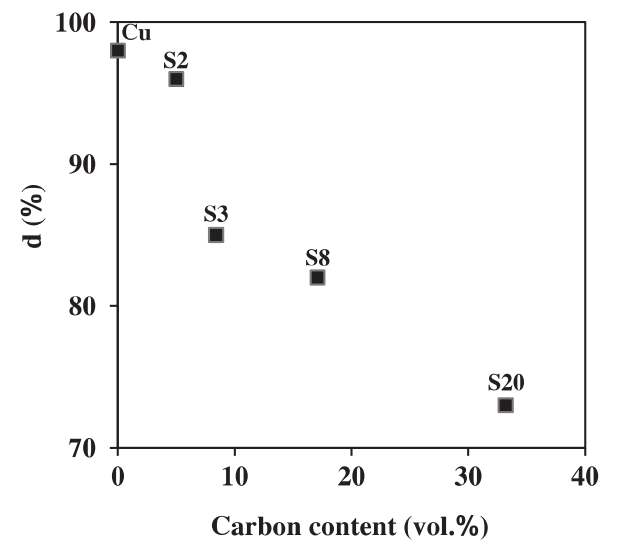

Fig. 5 - Relative density of the specimens prepared by SPS versus carbon content.

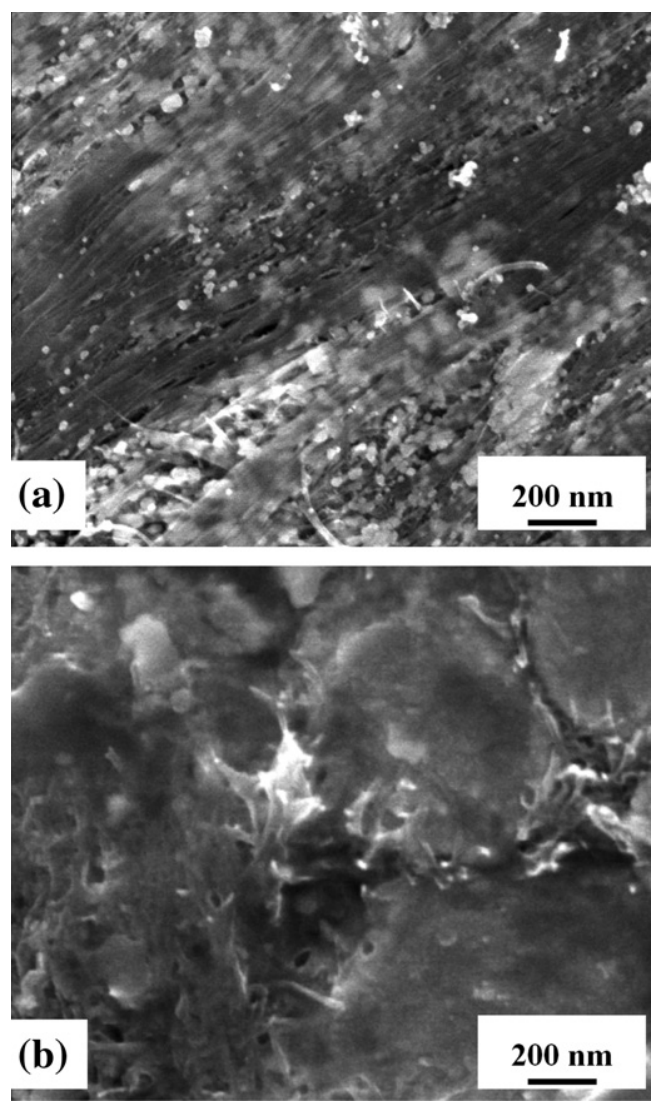

Fig. 6 - FESEM images of the polished and etched surface of specimens S2 (a) and S20 (b).

S8 (about 80), which is similar or slightly lower to what has been reported for other CNT/Cu composites [2-4,7-9] (Table 3). The trend is that it decreases with the increasing carbon content, which could reflect the decreasing relative density.

Typical curves showing the friction coefficient against a steel ball ( $1 \mathrm{~N}$ load) versus the number of cycles are shown in Fig. 8 (the curve for S8 was omitted for the sake of clarity). After a running-in period (about 100 cycles), the friction coefficient stabilizes at 0.9 for pure $\mathrm{Cu}$. For S2-S20, it stabilizes in

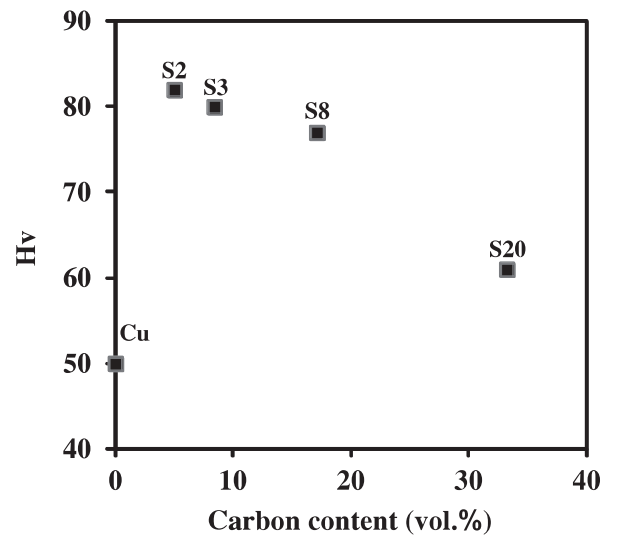

Fig. 7 - Vickers microhardness versus carbon content.

the range $0.15-0.30$. Moreover, the running-in period decreases from about 200 to about 10 cycles upon the increase of the number of walls. Once the contact is stabilized, a lower noise is observed for the composites than for $\mathrm{Cu}$. The behavior at $5 \mathrm{~N}$ load is similar. The observed noise on the curves (Fig. 8) reflects that the contact lacks stability and that a certain amount of wear occurs.

For both applied loads, the average friction coefficient (Fig. 9 and Table 2) decreases and reaches a plateau for S3S20, showing a fourfold decrease compared to $\mathrm{Cu}$. These results compare favorably with those reported by other researchers (Table 3). It is interesting to note that attempts to strengthen the interface between SWCNTs and $\mathrm{Cu}$ by using Ni-coated SWCNTs result in an increase of the friction coefficient over that found for pure $\mathrm{Cu}$ [5]. Data corresponding to DWCNT/Cu composites [9] are also shown in Fig. 9 (triangle symbols). The friction coefficients found for the present S3 specimen are in line with what would be obtained for the same carbon content ( $8.4 \mathrm{vol} . \%)$ using DWCNTs. Interestingly, for S8 $(17.1$ vol.\%,), the friction coefficient at both 1 and $5 \mathrm{~N}$ are two times lower than for the DWCNT/Cu composite with a similar carbon content (16 vol.\%). Moreover, despite a poor densification and a moderate microhardness, S20 (33.2 vol.\%) shows a friction coefficient (0.21) which is about 3 times lower than the one (ca. 0.6-0.7) coherent when comparing with the DWCNT/Cu data (Fig. 9).

After wear tests were performed, the half-width $(r)$ of the wear track was measured from white-light interferential rugosimetry images (Fig. 10) [21]. The wear tracks on Cu (Fig. 10a) and S20 (Fig. 10d) reveal important wear, contrasting with what is observed for S2 (Fig. 10b) and S8 (Fig. 10c). S3 (not shown) is similar to S2. The outer radius of the circular track $\left(\mathrm{L}^{\prime}\right)$ is equal to $4 \mathrm{~mm}$. Dark areas in the images correspond to areas not accessible to the white-light beam and therefore are deeper than the areas colored in blue. This corresponds to the samples showing high wear volume, as discussed below, which is not unexpected.

The wear volume $\left(V_{w}-\right.$ Fig. 11a and Table 2) was calculated for a half-ellipse track according to Eq. (1):

$\mathrm{V}_{\mathrm{W}}\left(\mathrm{mm}^{3}\right)=1 / 2 \cdot \pi r d \cdot 2 \pi \mathrm{L}$

with $r=$ track half-width $(\mathrm{mm}), d=$ track depth $(\mathrm{mm})$, $L^{\prime}=$ outer radius of the circular track $(4 \mathrm{~mm})$ 


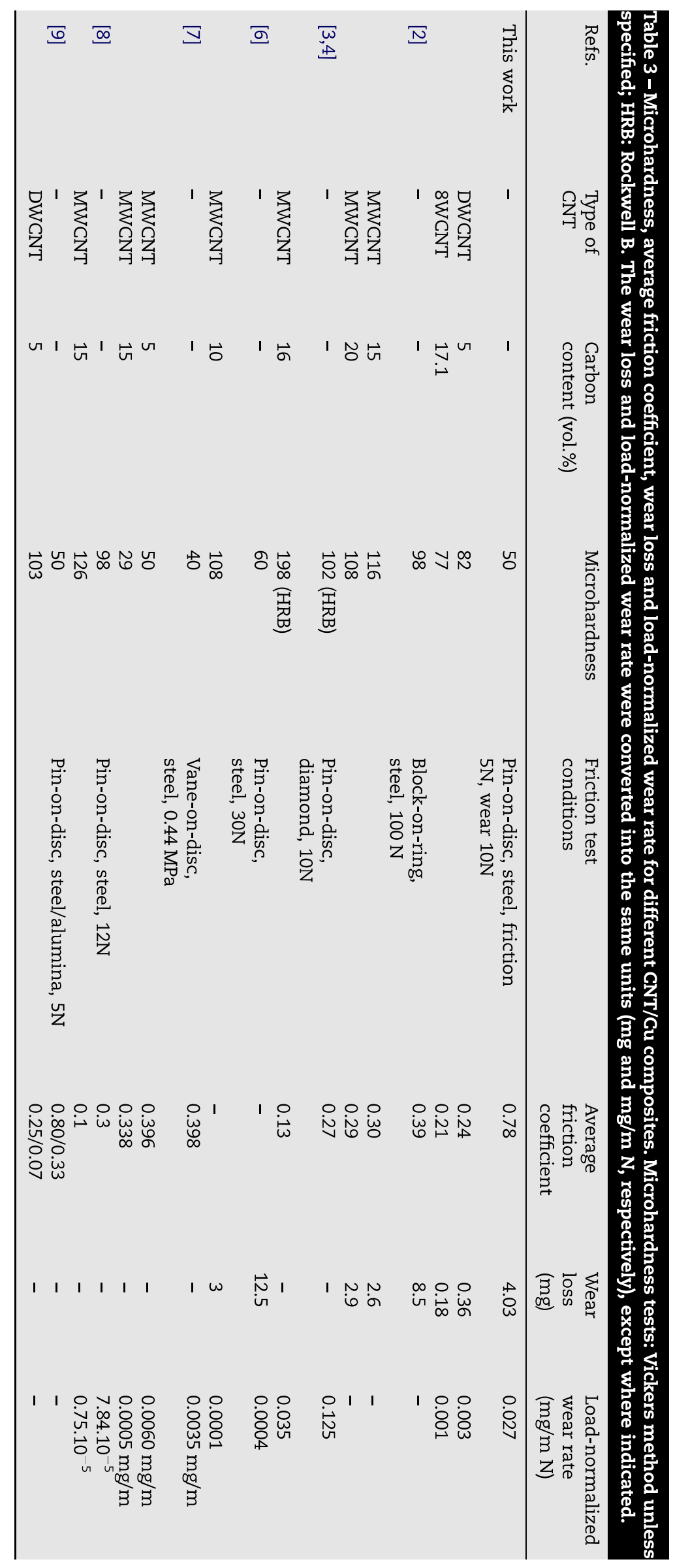




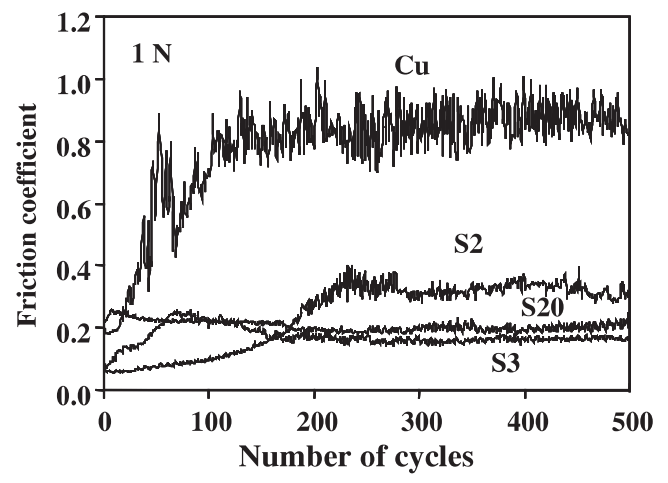

Fig. 8 - Friction coefficient against a steel ball versus the number of cycles for selected specimens. The test load is equal to $1 \mathrm{~N}$.

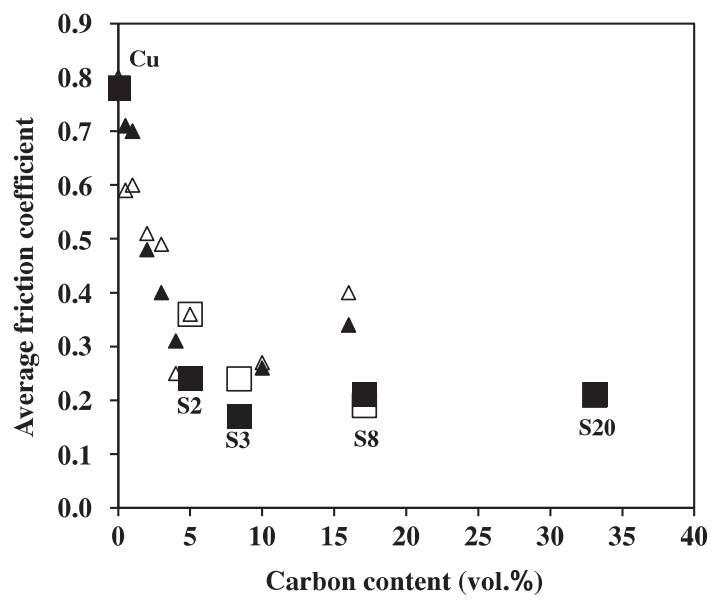

Fig. 9 - Average friction coefficient against a steel ball versus carbon content. Squares: this work. Triangles: DWCNT/Cu specimens [9]. Open symbols: $1 \mathrm{~N}$ load; solid symbols: $5 \mathrm{~N}$ load.

The load-normalized wear rate (W - Fig. 11b and Table 2) was calculated according to Eq. (2):

$\mathrm{W}\left(\mathrm{mm}^{3} / \mathrm{m} \cdot \mathrm{N}\right)=\mathrm{V}_{\mathrm{W}} /(\mathrm{L} \cdot \mathrm{F})$

with $L=$ sliding distance $(15 \mathrm{~m}), F=$ applied normal load $(10 \mathrm{~N})$

For both $S 2$ and $S 3, V_{w}$ and $W$ are about 10 times lower than for pure $\mathrm{Cu}$. The minimum is reached for $\mathrm{S} 8$, with $\mathrm{V}_{w}$ and $\mathrm{W}$ about 20 times lower than for $\mathrm{Cu}$. The values for $\mathrm{S} 20$ are higher than the values for S2-S8, reflecting the poor relative density of the specimen (i.e. the high residual porosity). Highlyporous composites show a decrease of their wear resistance notably under high-load [4]. However, the present load is moderate $(10 \mathrm{~N})$ and thus the severe wear regime is not established, which could account for the fact that despite a much lower relative density for S20 than for $\mathrm{Cu}(73 \%$ vs $95 \%)$, the former sample shows less wear. Wear data from the present study and other works $[3,4,6,8]$ were converted into mass units (as opposed to volume units) for the sake of comparison, using the density of pure $\mathrm{Cu}\left(8.96 \mathrm{~g} / \mathrm{cm}^{3}\right)$ for the sake of simplicity, and all wear rates were load-normalized (Table 3). The load-normalized wear rates are in a fairly wide range $\left(10^{-5}\right.$ to $\left.10^{-1} \mathrm{mg} / \mathrm{m} . \mathrm{N}\right)$, depending probably on the test conditions and wear regime (low, mild or severe) and on the density and polishing state of the specimens. A preliminary analysis of the worn surface of the steel ball found $\mathrm{Cu}$ and carbon transfer on the ball. FESEM observation of the worn surface of the S8 (Fig. 12a) revealed grooves, scars and plastic deformation of $\mathrm{Cu}$, suggesting abrasive and adhesive wear, as observed by several authors [2,6-8], reflecting that $\mathrm{Cu}$ grains wear out and that the subsurface is freshly exposed to the steel counterface, even for the moderate loads used in this study. A back-scattered electron image in chemical composition mode (Fig. 12b) of the same area reveals that the dark spots are CNT agglomerates.

Although a detailed investigation of the wear mechanisms as performed by other authors $[2,7,8]$ is well beyond the scope of this work and warrants further studies, it was found interesting to study the wear tracks by Raman spectroscopy. Typical Raman spectra for S2, S8 and S20, inside and outside the worn surface, are shown in Fig. 13.

Outside the worn surface, a large background signal is observed, while background is considerably reduced inside the worn surface and the CNT spectral bands are more intense. To understand the difference in the background signal, the Raman Stokes and anti-Stokes spectra were recorded. The Stokes signal is proportional to $n(\omega)+1$ (with $n(\omega)$ the Bose-Einstein factor) while the anti-Stokes signal is proportional to $n(\omega)$. The temperature can be roughly estimated through the relative intensity of the Stokes and anti-Stokes spectra using Eq. (3) [22]:

$\mathrm{T}=\hbar \omega /\left[k_{B} \cdot \ln \left(\mathrm{I}_{\mathrm{S}} / \mathrm{I}_{\mathrm{AS}}\right]\right.$

Temperatures of $400-500 \mathrm{~K}$ inside and outside the worn surface were deduced depending on location when considering the $200-400 \mathrm{~cm}^{-1}$ spectral range. This temperature increase is due to the laser power deposited on the sample. The probe depth of visible light in copper is very small (a few nanometers). $T(\omega)$ is constant in the considered spectral range indicating that the inelastic signal is a Raman signal. Moreover, no change in the background signal is observed when using 530 and $488 \mathrm{~nm}$ laser excitation. This shows that the background signal is not caused by luminescence but by Raman inelastic scattering with phonons and electrons. Thus, the higher background signal outside the track is attributed to the presence of a larger fraction of $\mathrm{Cu}$. The smaller background signal and higher intensities of the Raman bands thus show that the fraction of CNTs is higher in the worn surface. A more detailed analysis was performed in the track for S2. Indeed, DWCNTs have a characteristic $G$ band line shape due to inner and outer tubes [23], even if the pristine signal of DWCNTs is less defective (the pristine $A_{D} / A_{G}$ ratio of integrated intensities is lower than $20 \%$ with no significant $D^{\prime}$ band). Due to the huge background which saturates the spectrometer detector, an accurate analysis of the DWCNT Raman signal outside the track (Fig. 13a) is not possible. Interestingly, the line width and intensity of the $G$ band in the worn surface (Fig. 13d) indicate that the CNTs are still in cylindrical form with some possible local deformation and are not transformed in disordered forms of $\mathrm{sp}^{2}$ carbon. The $\mathrm{G}^{+}{ }_{\mathrm{i}}$ band from the inner tube is located at $1581 \mathrm{~cm}^{-1}$ and the $G^{+}$oband from 

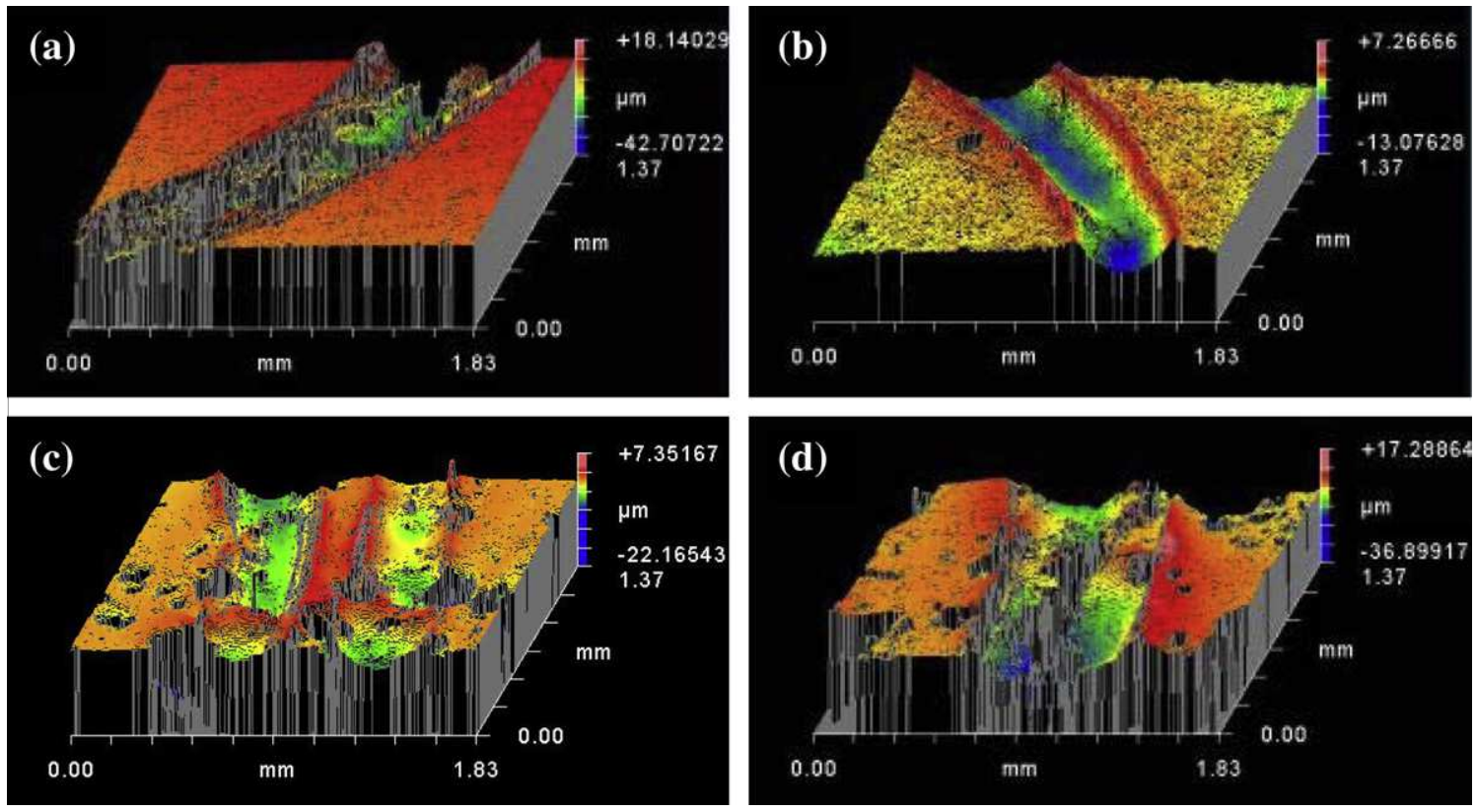

Fig. 10 - White-light interferential rugosimetry images of the wear track for Cu (a), S2 (b) S8 (c) and S20 (d). There are two tracks for S8.
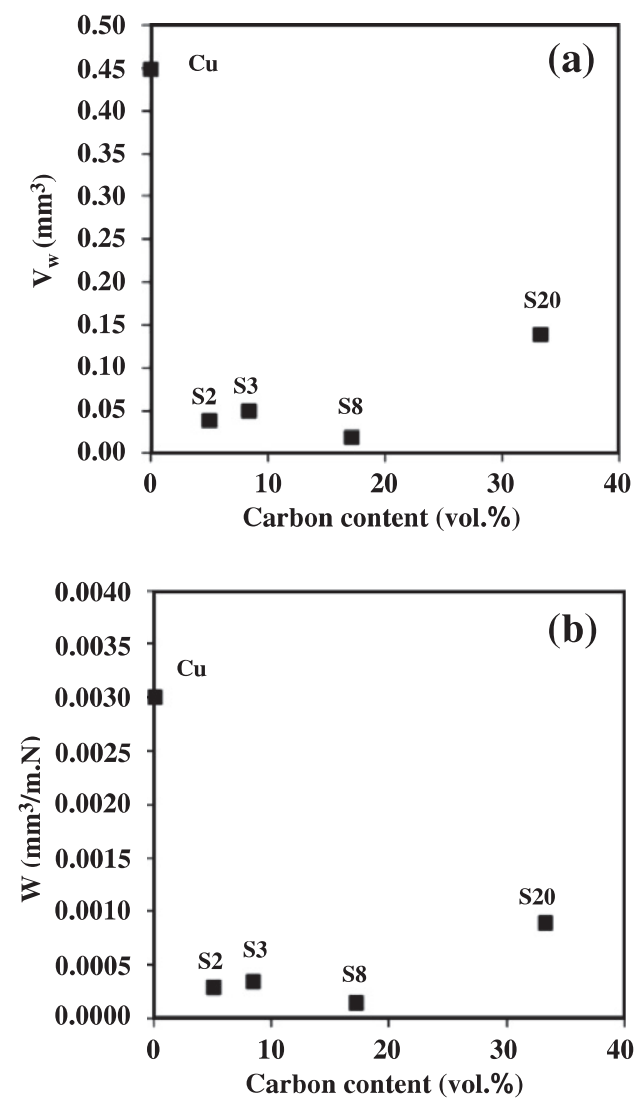

Fig. 11 - Wear volume (a) and load-normalized wear rate (b) versus carbon content.

the outer tube is located at $1592 \mathrm{~cm}^{-1}$ (Fig. 13d). The best spectral fitting was obtained when keeping fixed the $G^{+}{ }_{i}, G^{+}$o and $D^{\prime}$ bands line width and wave number and using the
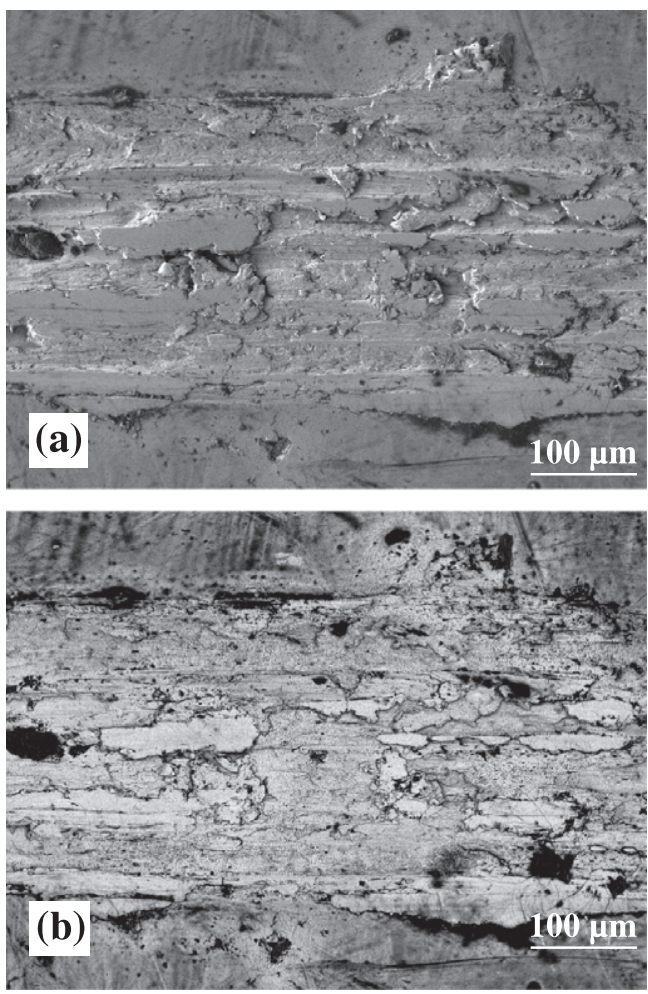

Fig. 12 - Typical FESEM image of friction track for S8 (a) and back-scattered electron image in chemical composition mode of the same area (b).

intensity of the three bands as free parameters. It was noticed that when using a single spectral band in the spectral range of the $G$ band, the spectral shifts so obtained are inconsistent with spectral shifts of the $D$ band. Using the $632 \mathrm{~nm}$ laser excitation, it is known that the $D$ and $D^{\prime}$ bands intensity is 

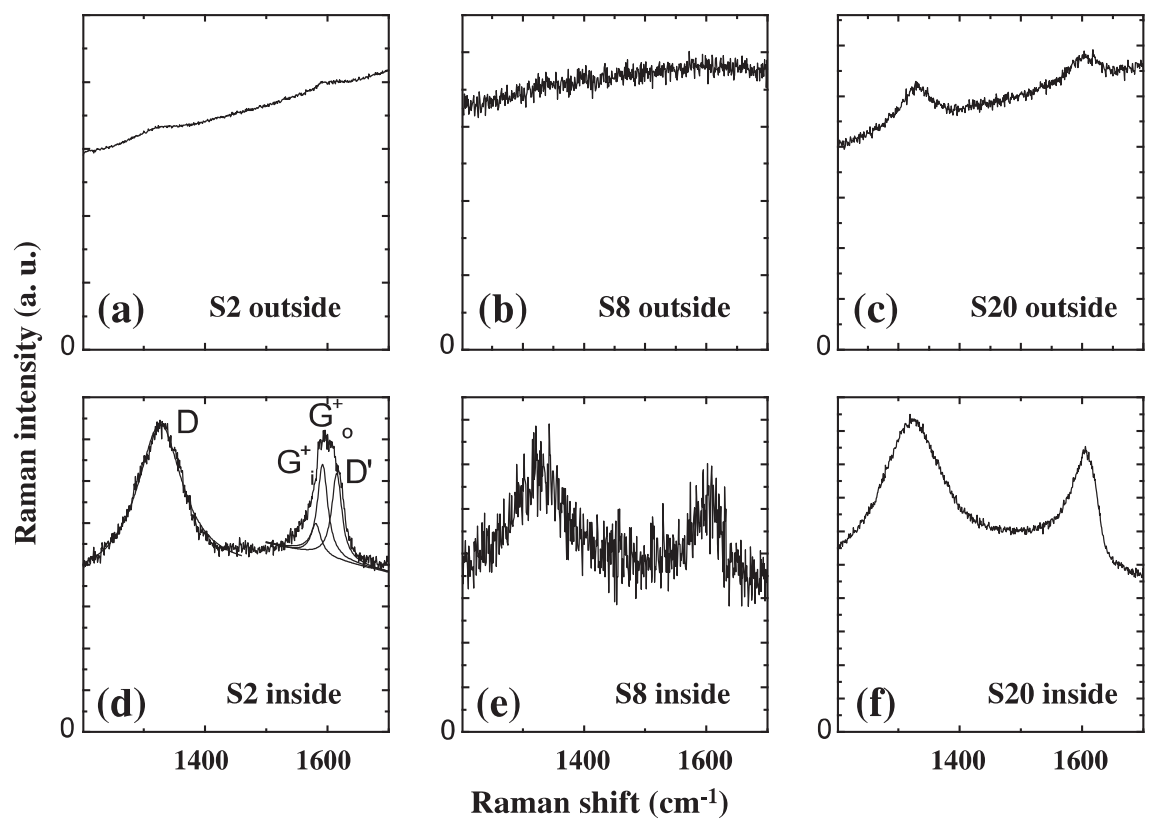

Fig. 13 - Typical Raman spectra outside the worn surface for S2 (a), S8 (b) and S20 (c) and inside the worn surface for S2 (d), S8 (e) and S20 (f). Spectra are plotted with the background signal.

higher [24], which makes it easier to separate the $D^{\prime}$ band from the $\mathrm{G}^{+}$band. The line width and intensity of the $G$ band in the worn surface (Fig. 13d) indicate that the DWCNTs are still present and are not transformed in disordered forms of $\mathrm{sp}^{2}$ carbon. Raman maps $\left(100 \times 100 \mu \mathrm{m}^{2}\right)$ in the worn surface (Fig. 14) were recorded by scanning the laser spot over the surface.

It is found that the D band shifts are small (Fig. 14a), indicating residual stress variations. The wave number for the $D$ band with pristine DWCNT is equal to $1324 \mathrm{~cm}^{-1}$. However, we are not sure that the comparison is meaningful because, due to non-adiabatic effects, phonon can be coupled to electron leading to a renormalization of the excitation. The present data do not permit to fully understand the possible effects of strain, doping and disorder. Full ab initio calculations will be the subject of future work. The $D$ band shift is correlated with the increase of the relative intensity of the $D^{\prime}$ band (Fig. 14b). It is noted that the $D$ and $D^{\prime}$ bands can be explained by inter-valley and intra-valley double resonant processes, respectively [25]. The $D^{\prime}$ band intensity is suspected to increase with the tube-tube interlayer interaction. This small increase of the $D^{\prime}$ band can thus be attributed be a reduction of the interlayer spacing consistent with a weak residual stress. This is consistent with the lower $G / D$ ratio indicating a larger number of defects (Fig. 14c). Some morphological changes consistent with FESEM images (Fig. 12) were also observed inside the track. These results are also consistent with pressure-induced DWCNT deformations, as discussed below. According to Caillier et al. [26], the first mechanical transition (ovalization), corresponding to a modification of the outer wall cross-section from circular to oval, could occur above $80 \mathrm{MPa}$ for DWCNTs with an outer diameter of $4 \mathrm{~nm}$. The second one (collapse), corresponding to the deformation of the outer wall into a peanut-like cross-section, could occur above $540 \mathrm{MPa}$. It was shown that in the case of DWCNTs, the sup- porting effect of the internal tube pushes the collapse pressure to higher values [27-30]. Due to the large number of defects, both the ovalisation and the collapse can be stabilized by bridging carbon bonds between the CNTs. These authors [26] note that the interaction with a substrate (here the matrix surface) should lead to a reduction of the ovalization onset. Moreover, stress deviatoric components, characteristic of the friction and wear experiments, should reduce the pressure values of cross-section modification as discussed by Merlen et al. [31]. The average and maximum Hertzian contact pressures sustained by the CNTs in the contact $\left(P_{\text {Hertz }}\right.$ and $P_{\max }$, respectively) were calculated from the ball-radius $(R)$, the applied load $(F)$, the Young modulus $(E)$ and Poisson coefficient ( $v$ of the counterparts, using Eqs. (4) and (5):

$P_{\text {Hertz }}=F / \pi a^{2}$

$P_{\max }=3 F / 2 \pi a^{2}$

where

the contact radius $a=\left(3 F R^{*} / 2 E^{*}\right)^{\frac{1}{3}}$

The equivalent contact radius $R^{*}$ and the equivalent Young modulus are defined as follows:

$R^{*}=R / 2$ (steel ball - plane contact)

$1 / E^{*}=\left(1-v_{\text {steel }}^{2}\right) / E_{\text {steel }}+\left(1-v_{\text {plane }}^{2}\right) / E_{\text {plane }}$

where $E_{\mathrm{Cu}}=100 \mathrm{GPa}, v_{\mathrm{Cu}}=0.33, E_{\text {steel }}=200 \mathrm{GPa}, v_{\text {steel }}=0.33$.

The $P_{\text {Hertz }}$ and $P_{\max }$ values are equal to 330 and $495 \mathrm{MPa}$, respectively for a $1 \mathrm{~N}$ load and to 565 and $850 \mathrm{MPa}$, respectively for a $5 \mathrm{~N}$ load. The comparison of $P_{\max }$ with the values reported by Caillier et al. [26] supports the Raman spectroscopy findings, indicating that the DWCNTs in the worn surface still present a cylindric shape, maybe cut but not in form of planar fragments that may have been formed by 

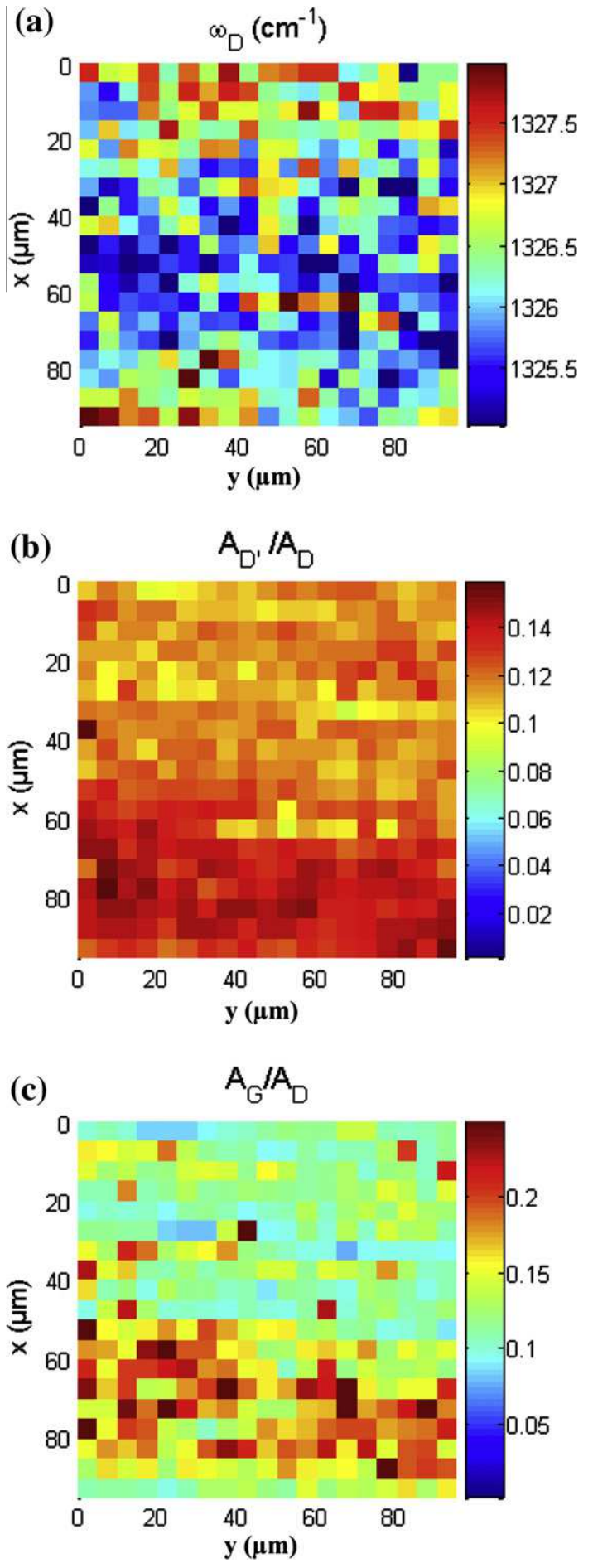

Fig. 14 - Raman maps $\left(100 \times 100 \mu \mathrm{m}^{2}\right)$ within the friction area for sample S2. $\omega_{\mathrm{D}}$ : wavenumber position of the $D$ band (a), $\omega_{D}=1324 \mathrm{~cm}^{-1}$ for pristine DWCNTs; $A_{D^{\prime}} / A_{D}$ : relative intensity of the $D^{\prime}$ band (b) using integrated intensity and $A_{G} / A_{D}$ relative intensity of the $G$ band (c) using integrated intensity.

exfoliation. Cutting (shortening) of CNTs under mechanical stress has been reported elsewhere [36]. Comparison with other data on the shearing of the DWCNTs walls [32,33] reveals that it could also occur, but clearly it is not the domi- nant mechanism. Bundle deformation could also be involved [37]. Such detailed analysis of the Raman spectra is not possible for S8 and S20 because the signal of the $G$ band is due to a broad $G$ band and a $D^{\prime}$ shoulder and the subtle changes observed with DWCNTs are difficult to track. However, the barriers for the relative axial sliding of adjacent walls, and hence the corresponding shear strengths, are reported to be negligible in MWCNTs [34]. A shear strength equal to only 0.04 MPa was measured for MWCNTs [35]. Thus, the 8WCNTs and 20WCNTs could be cut, producing shortened CNTs, and broken (exfoliated), thus contributing to the formation of a mechanically mixed carbonaceous layer, the nature of which is still unclear, into the contact. Cutting of CNTs under mechanical stress has been reported elsewhere [36]. This could limit the metal-metal contact and the seizing wear, as already suggested $[7,8]$. This could also result in a filling of the surface porosity, accounting for the low friction coefficient observed for samples of poor relative density (i.e. high volume residual porosity) and of low microhardness. As study on hollow, multilayered and highly faceted $\mathrm{WS}_{2}$ nanoparticles about $80-120 \mathrm{~nm}$ in diameter [38] revealed firstly that the presence of the hollow core gives the possibility for the external layers to first elastically deform before exfoliation and secondly that the presence of point defects in the particles facilitates easier exfoliation. Our results could imply that CNT deformation/collapse has a more positive influence than CNT exfoliation on friction and wear at least for the DWCNTs. It would thus be interesting to test higher-diameter DWCNTs. As noted above, it is not yet clear if exfoliation is occurring on a large scale for the 8WCNTs and 20WCNTs. Further experimental studies, as well as modeling, are warranted in order to determine the influence of CNT diameter and number of walls on mechanisms involving either CNT deformation/collapse or CNT exfoliation and in order to determine the most appropriate compromise for the design of materials well suited for particular friction or wear conditions.

\section{Conclusions}

CNT/Cu composites prepared using CNTs with a different number of walls (2, 3, 8 and 20) present a higher microhardness, a lower friction coefficient (by a factor of 3-4) and lower wear and wear rate against steel (by a factor of 10-20) compared to pure $\mathrm{Cu}$. An in-depth Raman spectroscopy study of the DWCNT/Cu specimen outside and inside the wear track indicates that the DWCNTs still exist in the track, with some residual strains. After $\mathrm{Cu}$ grains wear out, the subsurface is freshly exposed to the contact and the DWCNTs therein are not transformed into carbon debris. A comparison of the maximum Hertzian contact pressures sustained in the contact with literature data points to a mechanism involving ovalization and collapse of the DWCNTs. Tests involving higher-diameter DWCNTs is the subject of future work. Increasing the number of walls increases the volume carbon content, which hampers densification and thus decreases the microhardness. The composites prepared using DWCNTs, 3WCNTs and notably 8WCNTs shows particularly good results in friction and wear. Interestingly, the friction coefficients found for the present specimens are lower than those 
obtained for the same carbon content using only DWCNTs. CNTs with more walls and thus a higher diameter are less shear-resistant than DWCNTs and therefore it is probable that 8WCNTs and 20WCNTs are shortened and also broken (exfoliated) thus contributing to the formation of a mechanically mixed carbonaceous layer into the contact. This could result in a filling of the surface porosity, accounting for the low friction coefficient observed for samples of poor relative density and low microhardness. These results provide important guidelines for the design of self-lubricating CNT/Cu composites and future work directions include: (i) studies to determine the influence of CNT diameter and number of walls on mechanisms involving either CNT deformation/collapse or CNT exfoliation, (ii) an in-depth characterization of the microstructure, which notably depends on the number of CNTs (and therefore of a combination of number of walls and carbon loading) and (iii) a study of the transition into the severe-wear regime.

\section{Acknowledgements}

The FESEM observations were performed at TEMSCAN, the "Service Commun de Microscopie Electronique", Université Paul-Sabatier. The authors thank V. Foncrose for assistance for the wear tests and G. Chevallier for assistance with the SPS, which was performed at the Plateforme Nationale CNRS de Frittage Flash ( $\mathrm{PNF}^{2}$, Toulouse). This work is performed within the framework of the Fondation de Recherche pour l'Aéronautique et l'Espace program (FRAE AO4).

\section{R E F E R E N C E S}

[1] Bakshi SR, Lahiri D, Agarwal A. Carbon nanotube reinforced metal matrix composites - a review. Int Mater Rev 2010;55(1):41-64.

[2] Dong SR, Tu JP, Zhang XB. An investigation of sliding wear behavior of $\mathrm{Cu}$-matrix composite reinforced by carbon nanotubes. Mater Sci Eng A 2001;313(1-2):83-7.

[3] Tu JP, Yang YZ, Wang LY, Ma XC, Zhang XB. Tribological properties of carbon-nanotubes-reinforced copper composites. Tribo Lett 2001;10(4):225-8.

[4] Chen WX, Tu JP, Wang LY, Gan HY, Xu ZD, Zhang XB. Tribological application of carbon nanotubes in a metalbased composite coating and composites. Carbon 2003;41(2):215-22

[5] Lim B, Kim C, Kim B, Shim U, Oh S, Sung B, et al. The effects of interfacial bonding on mechanical properties of singlewalled carbon nanotube reinforced copper matrix nanocomposites. Nanotechnology 2006;17(23):5759-64.

[6] Kim KT, Cha SI, Hong SH. Hardness and wear resistance of carbon nanotube reinforced $\mathrm{Cu}$ matrix nanocomposites. Mater Sci Eng A 2007;449-451:46-50.

[7] Lin CB, Chang ZC, Tung YH, Ko YY. Manufacturing and tribological properties of copper matrix/carbon nanotubes composites. Wear 2011;270(5-6):382-94.

[8] Rajkumar K, Aravindan S. Tribological studies on microwave sintered copper-carbon nanotube composites. Wear 2011;270(9-10):613-21.

[9] Guiderdoni Ch, Estournès C, Peigney A, Weibel A, Turq V, Laurent $\mathrm{Ch}$. The preparation of double-walled carbon nanotube/Cu composites by spark plasma sintering, and their hardness and friction properties. Carbon 2011;49(13):4535-43.

[10] Laurent Ch, Flahaut E, Peigney A. The weight and densities of carbon nanotubes versus the number of walls and diameter. Carbon 2010;48(10):2989-99.

[11] Legorreta Garcia F, Estournès C, Peigney A, Weibel A, Flahaut E, Laurent $\mathrm{Ch}$. Carbon nanotube-magnesia nanocomposites by spark-plasma-sintering: microstructure, electrical conductivity and microhardness. Scripta Mater 2009;60(9):741-4.

[12] de Andrade MJ, Weibel A, Laurent Ch, Roth S, Pérez Bergmann, C, Estournès, et al. Electrical conductive doublewalled carbon nanotubes - silica glass nanocomposites prepared by the sol-gel process and spark plasma sintering. Scripta Mater 2009;61(10):988-91.

[13] Peigney A, Legorreta Garcia F, Estournès C, Weibel A, Laurent $\mathrm{Ch}$. Toughening and hardening in double-walled carbon nanotube/nanostructured magnesia composites. Carbon 2010;48(7):1952-60.

[14] Flahaut E, Bacsa R, Peigney A, Laurent Ch. Gram-scale CCVD synthesis of double-walled carbon nanotubes. Chem Commun 2003:1442-3.

[15] Flahaut E, Laurent Ch, Peigney A. Catalytic CVD synthesis of double and triple-walled carbon nanotubes by the control of the catalyst preparation. Carbon 2005;43(2):375-83.

[16] Flahaut E, Peigney A, Laurent Ch, Rousset A. Synthesis of single-walled carbon nanotubes -Co-MgO composite powders and extraction of the nanotubes. J Mater Chem 2000;10(2):249-52.

[17] Flahaut E, Peigney A, Bacsa WS, Bacsa RR, Laurent Ch. CCVD synthesis of carbon nanotubes from $(\mathrm{Mg}, \mathrm{Co}, \mathrm{Mo}) \mathrm{O}$ catalysts: influence of the proportions of cobalt and molybdenum. J Mater Chem 2004;14:646-53.

[18] Chiodarelli N, Richard O, Bender H, Heyns M, De Gendt S, Groeseneken G, et al. Correlation between number of walls and diameter in multiwall carbon nanotubes grown by chemical vapor deposition. Carbon 2012;50(5):1748-52.

[19] Peigney A, Laurent Ch, Flahaut E, Bacsa RR, Rousset A. Specific surface area of carbon nanotubes and bundles of carbon nanotubes. Carbon 2001;39(4):507-14.

[20] Kwon Y-S, Chung S-T, Lee S, Noh J-W, Park J-S, German RM. Development of carbon nanotube reinforced copper. Adv Powder Metall 2008;9:296-305.

[21] Rodriguez-Suarez T, Bartolomé JF, Smirnov A, Lopez-Esteban S, Torrecillas R, Moya JS. Sliding wear behaviour of alumina/ nickel nanocomposites processed by a conventional sintering route. J Eur Ceram Soc 2011;31(8):1389.

[22] Hayes W, Loudon R. Scattering of light by crystals. Mineola NY: Dover Science Books; 2004.

[23] Puech P, Ghandour A, Sapelkin A, Tinguely C, Flahaut E, Dunstan DJ, Bacsa W. Raman G-band in double wall carbon nanotubes combining p-doping and high pressure. Phys Rev B 2008;78(4). 045413:1-6.

[24] Dresselhaus MS, Jorio A, Souza Filho AG, Saito R. Defect characterization in graphene and carbon nanotubes using Raman spectroscopy. Phil Trans R Soc A 2010;368:5355-77.

[25] Reich S, Thomsen C, Maultzsch J. Carbon nanotubes: basic concepts and physical properties. Berlin: Wiley-VCH; 2004.

[26] Caillier Ch, Ayari A, Gouttenoire V, Benoit JM, Jourdain V, Picher $\mathrm{M}$, et al. An individual carbon nanotube transistor tuned by high pressure. Adv Funct Mater 2010;20(19):3330-5.

[27] Puech P, Hubel H, Dunstan DJ, Bacsa RR, Laurent C, Bacsa WS, et al. Discontinuous tangential stress in double wall carbon nanotubes. Phys Rev Lett 2004;93(9):095506.

[28] Arvanitidis J, Christofilos D, Papagelis K, Andrikopoulos KS, Takenobu T, Iwasa Y, et al. Pressure screening in the interior of primary shells in double-wall carbon nanotubes. Phys Rev B 2005;71:125404. 
[29] Gadagkar V, Saha S, Muthu D, Maiti PK, Lansac Y, Jagota A, et al. Double-walled carbon nanotubes under hydrostatic pressure: Raman experiments and simulations. J Nanosci Nanotechnol 2007;7(6):1753-9.

[30] Aguiar AL, Barros EB, Capaz RB, Souza Filho AG, Freire PTC, Mendes Filho J. Pressure-induced collapse in double-walled carbon nanotubes: chemical and mechanical screening effects. J. Phys. Chem. C 2011;115:5378-84.

[31] Merlen A, Toulemonde P, Le Floch S, Montagnac G, Hammouda T, Marty O, et al. High pressure-high temperature synthesis of diamond from single-wall pristine and iodine doped carbon nanotube bundles. Carbon 2009;47:1643-51.

[32] Li Y, Wang K, Wei J, Gu Z, Wang Z, Luo J, et al. Tensile properties of long aligned double-walled carbon nanotube strands. Carbon 2005;43(1):31-5.

[33] Bichoutskaia E, Ershova OV, Lozovik YE, Popov AM. Ab initio calculations of the walls shear strength of carbon nanotubes. Tech Phys Lett 2009;35(7):666-9.
[34] Lozovik YE, Popov AM. Properties and nanotechnological applications of nanotubes. Phys Usp 2007;50(7):749-61.

[35] Kis A, Jensen K, Aloni S, Mickelson W, Zettl A. Interlayer forces and ultralow sliding friction in multiwalled carbon nanotubes. Phys Rev Lett 2006;97(2):025501.

[36] Caillier Ch, Machon D, San-Miguel A, Arenal R, Montagnac G, Cardon $\mathrm{H}$, et al. Probing high-pressure properties of singlewall carbon nanotubes through fullerene encapsulation. Phys Rev B 2008;77(12):125418.

[37] Mylvaganam K, Zhang LC, Xiao KQ. Origin of friction in films of horizontally oriented carbon nanotubes sliding against diamond. Carbon 2009;7(7):1693-700.

[38] Lahouij I, Bucholz EW, Vacher B, Sinnott SB, Martin JM, Dassenoy F. Lubrication mechanisms of hollow-core inorganic fullerene-like nanoparticles: coupling experimental and computational works. Nanotechnology 2010;23(37):375701-10. 